Technische

Universität

Berlin

Kai Volgmann, Vanessa Werth, Suliman Nakhal, Martin Lerch, Thomas Bredow, Paul Heitjans

\title{
Solid-State NMR Spectroscopy Study of Cation Dynamics in Layered Na2Ti307 and Li2Ti307
}

Open Access via institutional repository of Technische Universität Berlin

Document type

Journal article | Published version

(i. e. publisher-created published version, that has been (peer-) reviewed and copyedited; also known as:

Version of Record (VOR), Final Published Version)

This version is available at

https://doi.org/10.14279/depositonce-12531

Citation details

Volgmann, K., Werth, V., Nakhal, S., Lerch, M., Bredow, T., \& Heitjans, P. (2017). Solid-State NMR

Spectroscopy Study of Cation Dynamics in Layered Na2Ti3O7 and Li2Ti3O7. In Zeitschrift für Physikalische Chemie (Vol. 231, Issues 7-8, pp. 1243-1262). Walter de Gruyter GmbH.

https://doi.org/10.1515/zpch-2016-0948

Terms of use

This work is protected by copyright and/or related rights. You are free to use this work in any way permitted by the copyright and related rights legislation that applies to your usage. For other uses, you must obtain permission from the rights-holder(s). 
Kai Volgmann*, Vanessa Werth, Suliman Nakhal, Martin Lerch, Thomas Bredow and Paul Heitjans*

\section{Solid-State NMR Spectroscopy Study of Cation Dynamics in Layered $\mathrm{Na}_{2} \mathrm{Ti}_{3} \mathrm{O}_{7}$ and $\mathrm{Li}_{2} \mathrm{Ti}_{3} \mathrm{O}_{7}$}

DOI 10.1515/zpch-2016-0948

Received December 7, 2016; accepted January 15, 2017

Abstract: Ti-based materials exhibit suitable properties for usage in secondary $\mathrm{Li}$ - and Na-ion batteries and were in the focus of several electrochemical and ion conductivity studies. A material of such interest is layer-structured, monoclinic $\mathrm{Na}_{2} \mathrm{Ti}_{3} \mathrm{O}_{7}$ Additionally, the sodium in $\mathrm{Na}_{2} \mathrm{Ti}_{3} \mathrm{O}_{7}$ can be replaced completely with lithium to achieve monoclinic $\mathrm{Li}_{2} \mathrm{Ti}_{3} \mathrm{O}_{\vec{p}}$, whose electrochemical properties were already investigated as well. Both materials exhibit interesting properties such as zero-strain behavior upon intercalation and high cycling stability. However, there is still a lack of fundamental understanding of the ion diffusivity of both $\mathrm{Na}$ and $\mathrm{Li}$ in the corresponding host structure. Solid-state nuclear magnetic resonance (NMR) spectroscopy is used here for the first time to reveal the cation dynamics in layered $\mathrm{Na}_{2} \mathrm{Ti}_{3} \mathrm{O}_{7}$ and $\mathrm{Li}_{2} \mathrm{Ti}_{3} \mathrm{O}_{7}$ This includes activation energies for the ionic motion and jump rates on the microscopic scale from NMR spin-lattice relaxation (SLR), spin-alignment echo (SAE), and 2D NMR exchange techniques. Moreover, the dimensionality of the ionic motion is investigated by frequency-dependent NMR SLR. Structural details are studied using magic-angle spinning (MAS) NMR spectroscopy. Results for the electric field gradient at the $\mathrm{Na}$ and Li site, respectively, are compared with those from theoretical calculations performed within

\footnotetext{
*Corresponding authors: Kai Volgmann and Paul Heitjans, Institut für Physikalische Chemie und Elektrochemie, Leibniz Universität Hannover, Callinstr. 3 - 3a, 30167 Hannover, Germany; and Zentrum für Festkörperchemie und Neue Materialien (ZFM), Leibniz Universität Hannover, Callinstr. 3 - 3a, 30167 Hannover, Germany, e-mail: volgmann@pci.uni-hannover.de (K. Volgmann); heitjans@pci.uni-hannover.de (P. Heitjans)
}

Vanessa Werth: Institut für Physikalische Chemie und Elektrochemie, Leibniz Universität Hannover, Callinstr. 3 - 3a, 30167 Hannover, Germany; and Mulliken Center for Theoretical Chemistry, Institut für Physikalische und Theoretische Chemie, Universität Bonn, Beringstr. 4, 53115 Bonn, Germany

Suliman Nakhal and Martin Lerch: Institut für Chemie, Technische Universität Berlin, Straße des 17. Juni 135, 10623 Berlin, Germany

Thomas Bredow: Mulliken Center for Theoretical Chemistry, Institut für Physikalische und Theoretische Chemie, Universität Bonn, Beringstr. 4, 53115 Bonn, Germany 
this study. The dynamics are similar for both cations, and the frequency-dependence of the ${ }^{7} \mathrm{Li}$ NMR SLR rate indicates Li motion confined to two dimensions. Thus, these two materials may be regarded a model system for low-dimensional diffusion of two different cations.

Keywords: diffusion; 2D NMR EXSY; ${ }^{6} \mathrm{Li}$ and ${ }^{7} \mathrm{Li} \mathrm{NMR}$; ${ }^{23} \mathrm{Na}$ NMR; solid-state NMR; spin-alignment echo; spin-lattice relaxation.

\section{Introduction}

Titanates and Ti-based materials have been in the focus of current research not only as anode materials for secondary Li-ion batteries but also as model systems for fundamental studies of Li motion. Titanates are widely investigated as alternative to graphite anodes as they exhibit, e.g. zero-strain behavior during cycling as well as high cycling stability. Besides $\mathrm{TiO}_{2}$, also various phases of the system $\mathrm{Li}_{2} \mathrm{O}-\mathrm{TiO}_{2}$ were studied with respect to their electrochemical behavior [1, 2]. A prominent example for fundamental studies of $\mathrm{Li}$ motion has been the $\mathrm{Li}_{x} \mathrm{TiS}_{2}$ system, see, e.g. [3-11]. But also other systems like $\mathrm{Li}_{x} \mathrm{TiO}_{2}$ and $\mathrm{Li}_{4} \mathrm{Ti}_{5} \mathrm{O}_{12}$ were investigated from the more fundamental point of view $[1,2,11-17]$.

The two materials investigated in the present work were already of interest in previous electrochemical studies. $\mathrm{Na}_{2} \mathrm{Ti}_{3} \mathrm{O}_{7}$ was studied with respect to its ionic conductivity $[18,19]$ as well as thermodynamic and electronic properties [20, 21]. Electrochemical methods like cyclovoltammetry and galvanostatic cycling were applied to $\mathrm{Li}_{2} \mathrm{Ti}_{3} \mathrm{O}_{7}$ [22]. Both materials exhibit a layered structure, which facilitates cation intercalation. While electrochemical consequences were investigated, there seem to be no fundamental diffusion studies comprising the questions how the microscopic motions of $\mathrm{Na}$ or Li take place in $\mathrm{Na}_{2} \mathrm{Ti}_{3} \mathrm{O}_{7}$ and $\mathrm{Li}_{2} \mathrm{Ti}_{3} \mathrm{O}_{7}$ and what the influence of a possible low-dimensional cation motion is. A fundamental understanding of the ionic motion is not only of interest for improvements in material design for battery applications. It is also essential for model systems, which exhibit correlated or low-dimensional diffusion, in order to compare experimental results with theoretical predictions.

Our present work investigates basic parameters of the ionic motion in $\mathrm{Na}_{2} \mathrm{Ti}_{3} \mathrm{O}_{7}$ and $\mathrm{Li}_{2} \mathrm{Ti}_{3} \mathrm{O}_{7}$ Solid-state nuclear magnetic resonance (NMR) provides several methods to study ionic mobility in condensed matter [23-26]. These methods are distinguished by the different time scales on which they are able to detect the ionic motion and therefore complement each other thus covering a wide range of ion jump rates. $\mathrm{Na}_{2} \mathrm{Ti}_{3} \mathrm{O}_{7}$ and $\mathrm{Li}_{2} \mathrm{Ti}_{3} \mathrm{O}_{7}$ are both characterized in phase composition and morphology using X-ray diffraction and scanning electron microscopy. 
Structural details are revealed by ${ }^{23} \mathrm{Na},{ }^{6} \mathrm{Li}$ and ${ }^{7} \mathrm{Li}$ magic-angle spinning (MAS) NMR spectroscopy. Information on ion mobility is gained by ${ }^{23} \mathrm{Na},{ }^{6} \mathrm{Li}$ and ${ }^{7} \mathrm{Li} \mathrm{NMR}$ spin-lattice relaxation (SLR), spin-alignment echo (SAE), and 2D NMR exchange spectroscopy (EXSY). This includes activation energies for the ion jumps, jump rates and the diffusion pathway. The dimensionality of the diffusion pathway is obtained by the analysis of the frequency dependence of the high-temperature flank of SLR rate peaks.

\section{Experimental and computational procedures}

\subsection{Preparation}

Samples were prepared using a solid-state synthesis route. First, monoclinic $\mathrm{Na}_{2} \mathrm{Ti}_{3} \mathrm{O}_{7}$ was synthesized analogously to the route described in [22, 27]. A mixture of $\mathrm{Na}_{2} \mathrm{CO}_{3} \cdot \mathrm{H}_{2} \mathrm{O}$ (99.5\% pure, Sigma-Aldrich) and $\mathrm{TiO}_{2}$ (99.9 \% pure, Merck) in a molar ratio of $1: 3$ was heated at $1123 \mathrm{~K}$ for $20 \mathrm{~h}$ in air. Monoclinic $\mathrm{Li}_{2} \mathrm{Ti}_{3} \mathrm{O}_{7}$ was prepared from $\mathrm{Na}_{2} \mathrm{Ti}_{3} \mathrm{O}_{7}$ via ion exchange at low temperature. Sodium/lithium ion exchange experiments were performed using the molten salt of an eutectic mixture of $\mathrm{LiNO}_{3}$ and $\mathrm{LiCl}$ (12 mol-\%) [18]. The prepared $\mathrm{Na}_{2} \mathrm{Ti}_{3} \mathrm{O}_{7}$ powder was added to the molten salt at $553 \mathrm{~K}$ and the ion exchange reaction was carried out at $533 \mathrm{~K}$ for $10 \mathrm{~h}$ in air. The reaction mixture was washed with ethanol and then dried at $373 \mathrm{~K}$ for 1 day in air.

\subsection{X-ray diffraction and scanning electron microscopy}

X-ray diffraction was performed on a "PANalytical X'Pert PROMPD" diffractometer equipped with a "PIXcel" detector using nickel-filtered $\mathrm{Cu}-\mathrm{K}_{\alpha}$ radiation $\left(\lambda_{1}=154.056 \mathrm{pm}, \lambda_{2}=154.439 \mathrm{pm}\right)$ in Bragg-Brentano $(\theta-\theta)$ geometry.

For Rietveld refinement, a known model for $\mathrm{Li}_{2} \mathrm{Ti}_{3} \mathrm{O}_{7}[28]$ from the inorganic crystal structure database (ICSD) [29] was imported, adjusted to reflect the actual cell parameters and contents, and refined against net intensities with FULLPROF [30] using the fullmatrix least-squares algorithm with fixed elements per cycle. The background was defined manually with 19 points of refined height. Peak profiles were fitted with a pseudo-Voigt function (Gaussian parameters U, V, and W; Lorentzian parameter X; mixing parameter $\eta$ ). A scale factor and a zero-shift correction were applied. The crystal structure was plotted using literature data and the program Diamond 3 [31]. 
Scanning electron microscopy (SEM) micrographs were recorded in secondary electron contrast with a JEOL JSM-6700F instrument using a cold-field emission gun with an acceleration voltage in the range $2-5 \mathrm{kV}$ and an emission current of $10 \mu \mathrm{A}$.

\subsection{Solid-state NMR spectroscopy}

Solid-state NMR spectroscopy measurements were conducted at a Bruker Biospin Avance III 600 spectrometer in combination with a shimmed cryomagnet Bruker Biospin Ultrashield 600 WB Plus. This cryomagnet operates at a nominal magnetic field of $B_{0}=14.1 \mathrm{~T}$ which corresponds to Larmor frequencies of $\omega_{0} / 2 \pi=88.3 \mathrm{MHz}$ for ${ }^{6} \mathrm{Li}, \omega_{0} / 2 \pi=233.3 \mathrm{MHz}$ for ${ }^{7} \mathrm{Li}$ and $\omega_{0} / 2 \pi=158.8 \mathrm{MHz}$ for ${ }^{23} \mathrm{Na}$. Two different commercial NMR probes were operated for ${ }^{6} \mathrm{Li},{ }^{7} \mathrm{Li}$ and ${ }^{23} \mathrm{Na}$ NMR measurements. On the one hand, a Bruker broadband single-channel NMR probe was used for static ${ }^{7} \mathrm{Li}$ and ${ }^{23} \mathrm{Na}$ NMR spectra as well as for ${ }^{7} \mathrm{Li}$ and ${ }^{23} \mathrm{Na}$ NMR spin-lattice relaxometry and ${ }^{7} \mathrm{Li}$ SAE NMR. The measurements were performed in a temperature range from $295 \mathrm{~K}$ to $473 \mathrm{~K}$. On the other hand, a Bruker two-channel MAS NMR probe was employed for recording ${ }^{6} \mathrm{Li}$, ${ }^{7} \mathrm{Li}$ and ${ }^{23} \mathrm{Na}$ NMR spectra and for ${ }^{6} \mathrm{Li} 2 \mathrm{D}$ NMR EXSY. This probe applies $\mathrm{ZrO}_{2}$ rotors with $2.5 \mathrm{~mm}$ in diameter and supports spinning rates up to $v=30 \mathrm{kHz}$. Measurements were conducted at $325 \mathrm{~K}$, which is the corrected temperature taking into account the heating due to MAS rotation. Temperature calibration for this probe was carried out using the temperaturedependent chemical shift of ${ }^{79} \mathrm{Br}$ of $\mathrm{KBr}$ [32].

${ }^{6} \mathrm{Li},{ }^{7} \mathrm{Li}$ and ${ }^{23} \mathrm{Na}$ NMR spectra - both under static and under MAS conditions - were obtained by Fourier transformation of free induction decays (FID) with the FID recorded using a single-pulse experiment with sufficiently large recycle delay time. ${ }^{7} \mathrm{Li}$ and ${ }^{23} \mathrm{Na}$ NMR SLR rates in the laboratory frame of reference were measured using the saturation recovery pulse sequence [33]. The sample was irradiated with $10 \pi / 2$ pulses within a few microseconds. Then the recovery of the magnetization $M$ started from zero back to equilibrium magnetization. The magnetization transients were fitted with the stretched exponential function $M_{z}(t)=M_{z, 0}\left\{1-\exp \left[-\left(t / T_{1}\right) \gamma\right]\right\}$ to calculate the SLR rate $1 / T_{1}$. The stretching exponent $\gamma$ varied around $0.8 \pm 0.1$. ${ }^{7} \mathrm{Li}$ NMR SLR in the rotating frame of reference (SLR $\rho$ ) was employed to access lower angular frequencies $\omega_{1}$ [33-36] and thus slower diffusion processes. These frequencies $\omega_{1} / 2 \pi$ were in the order of $10 \mathrm{kHz}$ instead of the order of $100 \mathrm{MHz}$. The spin-lock technique was used for measuring ${ }^{7}$ Li NMR SLR $\rho$. Starting with a $\pi /\left.2\right|_{\chi^{\prime}}$ pulse, a "spin lock" $\pi /\left.2\right|_{y^{\prime}}$ pulse with variable pulse length is applied to create an effective magnetic field parallel to the external magnetic field. Due to the used RF irradiation the achieved field strengths are 3-4 
orders of magnitude lower than the external magnetic field. The FID is recorded after the spin-lock pulse and different pulse lengths are used to obtain a magnetization transient. A recycle delay of $5 \times T_{1}$ was used. The fit of the transients was again carried out using a stretched exponential function. The exponent $\gamma$ varied between 0.2 and 0.6 . The SLR $\rho$ rate was evaluated for different temperatures and for different frequencies $\omega_{1} / 2 \pi$. These frequencies were $\omega_{1} / 2 \pi=10,15$ and $20 \mathrm{kHz}$.

${ }^{7} \mathrm{Li}$ NMR SAE measurements were carried out using the Jeener-Broekaert pulse sequence $[7,37-42]$. SAE were recorded as a function of mixing time $t_{\mathrm{m}}$. Also echoes for various preparation times $t_{\mathrm{p}}$ were observed. The recycle delay was set to $5 \times T_{1}$. The pulse length for the $\pi / 2$ pulse was set to $3.5 \mu$ s for a non-selective excitation. Phase cycling according to a sin-sin two-time correlation function $S\left(t_{\mathrm{p}}, t_{\mathrm{m}}\right)$ was employed. For fixed $t_{\mathrm{p}}, S\left(t_{\mathrm{m}}\right)$ was recorded for a temperature range from 273 to $450 \mathrm{~K}$. ' $\mathrm{Li} 2 \mathrm{D}$ NMR EXSY was carried out using a pulse sequence consisting of three $\pi / 2$ pulses with appropriate phase cycling and a recycle delay of $5 \times T_{1}$ [43]. Additionally, the States-time proportional phase incrementation (States-TPPI) scheme was employed [44]. The first two pulses are separated by a delay for data acquisition. The delay between the second and the third pulse is denoted as mixing time. The mixing time was varied in separate experiments in order to obtain a transient of the cross peak intensities. These intensities were fitted using a stretched exponential.

\subsection{Theoretical calculation of electric field gradients}

The theoretical calculation of the electric field gradient was performed using the plane-wave program package VASP [45-48] in combination with the PBE functional $[49,50]$. For the core electron representation the projector-augmented wave (PAW) method was employed [51, 52]. An energy converged cutoff of $1200 \mathrm{eV}$ was used for the calculation. The integration in reciprocal space was performed with a $\Gamma$-centered $8 \times 4 \times 8$ Monkhorst-Pack (MP) k-point grid [53]. The experimental lattice parameters were used $[22,27]$ and the atomic positions were optimized prior to calculating the electric field gradients.

\section{Results}

\subsection{XRD and SEM}

X-ray powder diffraction and scanning electron microscopy were used to check the crystal structure of $\mathrm{Na}_{2} \mathrm{Ti}_{3} \mathrm{O}_{7}$ and $\mathrm{Li}_{2} \mathrm{Ti}_{3} \mathrm{O}_{7}$ before and after ion exchange. Accord- 


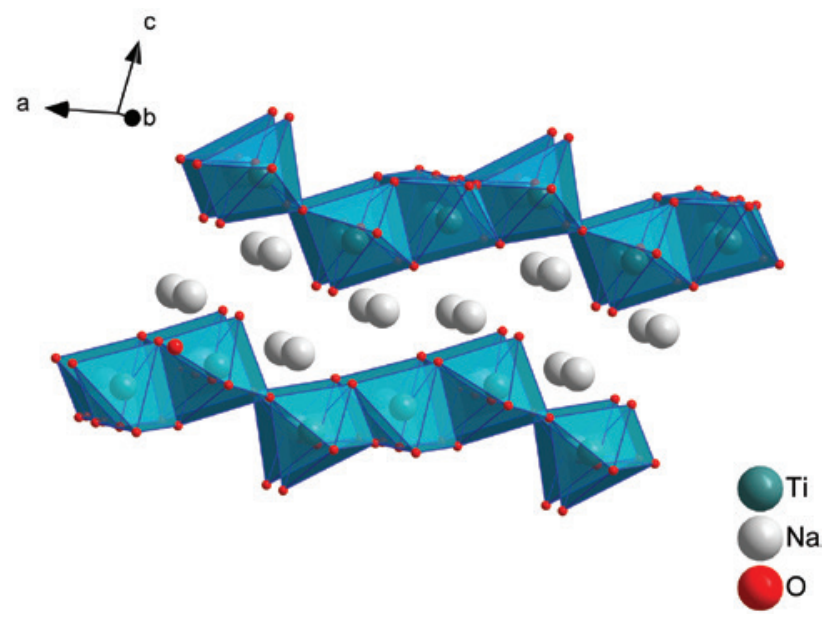

Fig. 1: Crystal lattice structure of monoclinic $\mathrm{Na}_{2} \mathrm{Ti}_{3} \mathrm{O}_{7}$ (space group $\mathrm{P}_{1} / \mathrm{m}$ ) plotted using Diamond 3 (Crystal Impact). Crystallographic data from [22, 27] was used for the plotting. Ti atoms are octahedrally coordinated by oxygen atoms. $\mathrm{Ti}_{3} \mathrm{O}_{7}$ layers are formed parallel to the $a b$ plane. In the gap between these layers, either $\mathrm{Na}$ or Li can occupy two crystallographic positions.

ing to literature [22, 27, 54], both $\mathrm{Na}_{2} \mathrm{Ti}_{3} \mathrm{O}_{7}$ and $\mathrm{Li}_{2} \mathrm{Ti}_{3} \mathrm{O}_{7}$ exhibit a monoclinic $\mathrm{P} 2 / \mathrm{m}$ space group and the cations are hosted within the $\mathrm{Ti}_{3} \mathrm{O}_{7}$ layers (Figure 1). There are two different types of cation positions, both described by the Wyckoff symbol 40. One is coordinated by oxygen within a prism, the other within an octahedra. According to this different coordination, the electric field gradients at the site of the cation should be different and discernible in the NMR spectra. Both XRD patterns (Figure 2a and b) show good qualitative agreement of our synthesized samples with literature data. Additionally, the patterns for $\mathrm{Na}_{2} \mathrm{Ti}_{3} \mathrm{O}_{7}$ and for $\mathrm{Li}_{2} \mathrm{Ti}_{3} \mathrm{O}_{7}$ were analysed using the Rietveld method, which confirmed the single phase of monoclinic $\mathrm{Na}_{2} \mathrm{Ti}_{3} \mathrm{O}_{7}$ and of monoclinic $\mathrm{Li}_{2} \mathrm{Ti}_{3} \mathrm{O}_{\overrightarrow{7}}$ respectively. Furthermore, our NMR results did not show additional signals in any spectra. SEM micrographs of $\mathrm{Na}_{2} \mathrm{Ti}_{3} \mathrm{O}_{7}$ and $\mathrm{Li}_{2} \mathrm{Ti}_{3} \mathrm{O}_{7}$ (Figure $2 \mathrm{c}$ and $\mathrm{d}$ ) showed the same shape and average particle size. In both cases, the particles exhibited a flake-like shape and the particle dimensions were in the micrometer range. The ion exchange had no effect on neither the host structure nor the morphology of the particles.

\subsection{Solid-state NMR: structure}

Figure 3 displays a ${ }^{23} \mathrm{Na}$ NMR spectrum recorded at $T=325 \mathrm{~K}$ under magic angle spinning (MAS) at a spinning rate of $v=30 \mathrm{kHz}$. The spectrum exhibits two features 


\section{a}

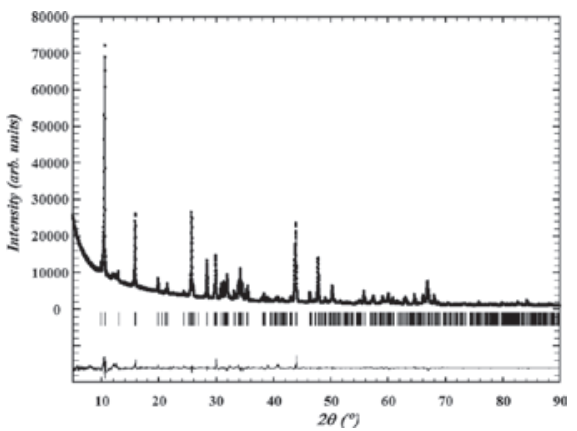

C

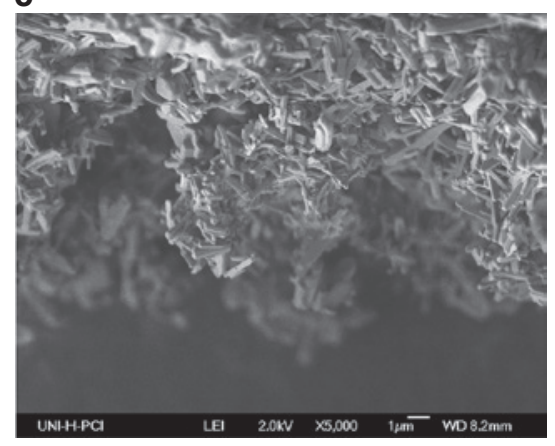

b

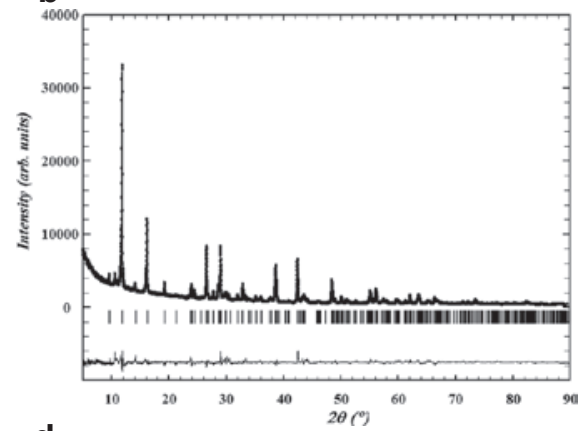

d

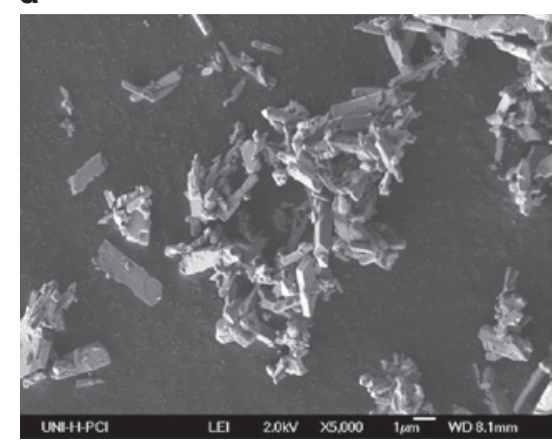

Fig. 2: (a) XRD pattern of monoclinic $\mathrm{Na}_{2} \mathrm{Ti}_{3} \mathrm{O}_{7}$. The obtained pattern shows good agreement with literature data [55]. (b) XRD pattern of monoclinic $\mathrm{Li}_{2} \mathrm{Ti}_{3} \mathrm{O}_{7}$. Rietveld analysis confirms the single phase of $\mathrm{Li}_{2} \mathrm{Ti}_{3} \mathrm{O}_{7}$ and yielded the lattice parameters to be $a=931.57(6) \mathrm{pm}, b=375.35(6)$ $\mathrm{pm}, c=754.88(12) \mathrm{pm}$, and $\beta=97.612(4)^{\circ}$. Thus, the ion exchange reaction left the parent structure intact and Li was successfully inserted and the sodium was replaced. (c) SEM micrograph of $\mathrm{Na}_{2} \mathrm{Ti}_{3} \mathrm{O}_{7}$. It shows agglomerated micrometer-size flakes with a regular shape. (d) After ion exchange, the shape and size of the particles of $\mathrm{Li}_{2} \mathrm{Ti}_{3} \mathrm{O}_{7}$ did not change.

which can be clearly distinguished. The two visible contributions correspond to the different Na positions. These NMR lines are denoted by $\mathrm{Na}(1)$ and $\mathrm{Na}(2)$. A fit of both lines was performed using dmfit [56]. The fit of the NMR spectrum yields the parameters of the electric field gradient (EFG) and can be used to assign the contributions to the two different crystallographic sites. $\mathrm{Na}(1)$ exhibits a broad line which can be fitted giving a quadrupolar coupling constant $C_{\mathrm{Q}, 1}=3.33 \mathrm{MHz}$ and an asymmetry parameter $\eta_{Q, 1}=0.56$. The high magnitude of the EFG hints to a lower coordination and higher asymmetry at this site. Therefore, $\mathrm{Na}(1)$ is assigned to the crystallographic site within the prism. For $\mathrm{Na}(2)$, a narrow line is observed corresponding to a $C_{\mathrm{Q}, 2}=0.86 \mathrm{MHz}$ and an asymmetry parameter $\eta_{\mathrm{Q}, 2}=0.70$. This NMR line can be assigned to the crystallographic site within the octahedra due to its higher coordination and symmetry. The results for the electric field gradient 


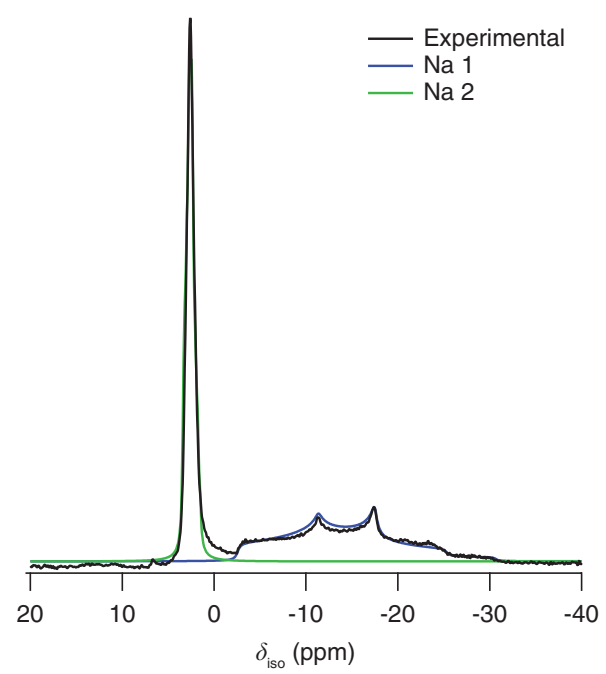

Fig. 3: ${ }^{23} \mathrm{Na}$ NMR MAS spectrum of $\mathrm{Na}_{2} \mathrm{Ti}_{3} \mathrm{O}_{7}$ recorded at the Larmor frequency of $\omega_{0} / 2 \pi=158.8 \mathrm{MHz}$. The spectrum is referenced to $1 \mathrm{M} \mathrm{NaCl}$ solution. The pulse length for the $\pi / 2$ pulse was set to $1 \mu \mathrm{s}$ for a non-selective excitation. The sample was rotated at a spinning rate of $30 \mathrm{kHz}$. This leads to a corrected sample temperature of $327 \mathrm{~K}$. The fit of the spectrum was carried out using dmfit [56]. For both contributions, the model for quadrupolar interaction of half-integer nuclear spins under MAS was used. The fit results yielded the EFG parameters summarized in Table 1.

tensor components were compared with VASP calculations. The results yielded $C_{Q, 1}=4.03 \mathrm{MHz}$ and $\eta_{\mathrm{Q}, 1}=0.22$ for the $\mathrm{Na}(1)$ site and $C_{\mathrm{Q}, 2}=1.25 \mathrm{MHz}$ and $\eta_{\mathrm{Q}, 2}=0.60$ for the $\mathrm{Na}$ (2) site. Deviations between experiment and calculation are ascribed to the employed routine in VASP. However, the trend for the EFG tensor components was reproduced and the assignment of the signals to the corresponding crystallographic sites was confirmed.

Structural information on $\mathrm{Li}_{2} \mathrm{Ti}_{3} \mathrm{O}_{7}$ could already be extracted from static ${ }^{7} \mathrm{Li}$ NMR spectra. In Figure 4a, ${ }^{7} \mathrm{Li}$ NMR spectra for a temperature range from 213 to $473 \mathrm{~K}$ are presented. Regarding the quadrupolar satellites, two contributions were observed. The quadrupolar coupling constant for both signals were calculated according to $C_{Q}=2 \Delta v_{\mathrm{Q}}$ assuming axial symmetry $(\eta=0)$ [57]. For the outer signals $\Delta v_{0,1}$ amounts to $56 \mathrm{kHz}$ for temperatures up to $373 \mathrm{~K}$. A narrowing of this contribution was observed above $373 \mathrm{~K}$. The position also shifted and led to a decrease of $\Delta v_{\mathrm{Q}, 1}$ to $51 \mathrm{kHz}$. Up to $373 \mathrm{~K}, C_{\mathrm{Q}, 1}$ is equal to $112 \mathrm{kHz}$ and above $373 \mathrm{~K}, C_{\mathrm{Q}, 1}$ takes a value of $102 \mathrm{kHz}$. Thus, the strength of the electric field gradient decreased by 10 $\mathrm{kHz}$. A possible reason may be a temperature-related relaxation of the lattice at this specific Li site. This relaxation of the crystal lattice may have also led to the 

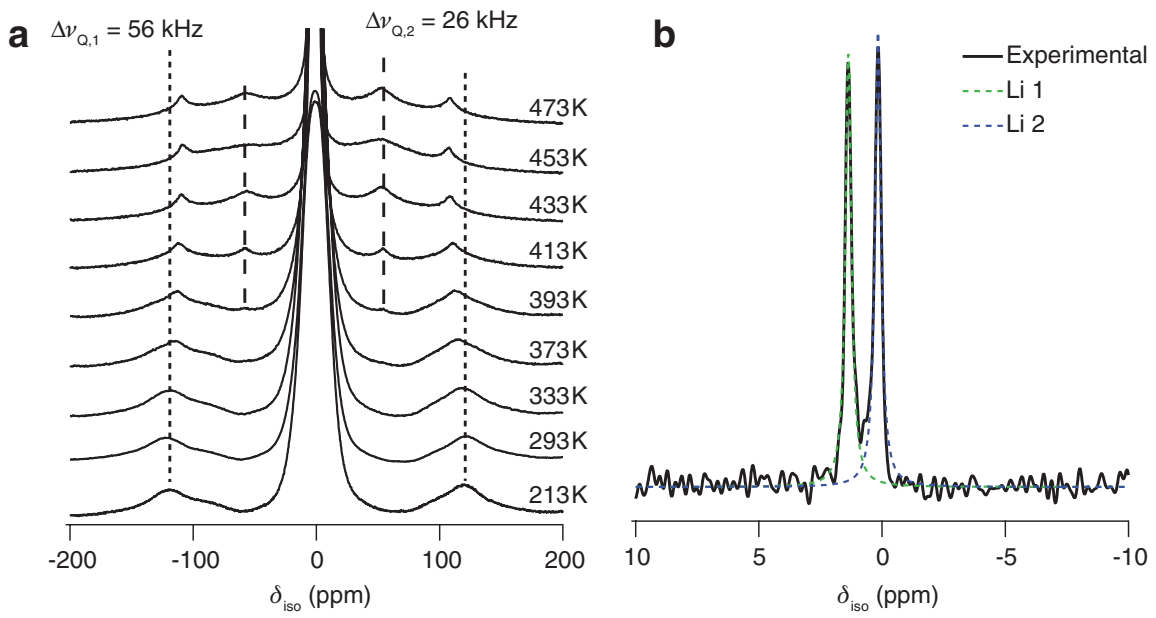

Fig. 4: (a) ${ }^{7} \mathrm{Li}$ static NMR spectra of $\mathrm{Li}_{2} \mathrm{Ti}_{3} \mathrm{O}_{7}$ recorded at the Larmor frequency of $\omega_{0} / 2 \pi=233.3 \mathrm{MHz}$ (offset $-213.6 \mathrm{~Hz}$ ). The pulse length for the $\pi / 2$ pulse was set to $3.5 \mu \mathrm{s}$. Spectra were recorded for a temperature range of $213 \mathrm{~K}-473 \mathrm{~K}$. The intensities of all spectra were normalized with respect to the central line. For better understanding, all spectra were scaled with respect to the quadrupolar satellites. The dashed lines are a guide to the eye for the positions of these satellites. The short-dashed lines mark the position of $\Delta v_{Q, 1}$, the longdashed ones mark the position of $\Delta v_{Q, 2}$ (b) ${ }^{6} \mathrm{Li}$ NMR MAS spectrum obtained at the Larmor frequency $\omega_{0} / 2 \pi=88.3 \mathrm{MHz}$ ( $1 \mathrm{M} \mathrm{LiCl}$ reference). The pulse length for the $\pi / 2$ pulse was set to 7.5 $\mu \mathrm{s}$. The sample was rotated at a spinning rate of $15 \mathrm{kHz}$ corresponding to a sample temperature of $300 \mathrm{~K}$. The spectrum was fitted using dmfit yielding the integrals of both contributions. The integrals were used to estimate the population found to be equal for both sites.

appearance of the second quadrupolar satellite. This is described by $\Delta v_{\mathrm{Q}, 2}=26 \mathrm{kHz}$ and $C_{\mathrm{Q}, 2}=52 \mathrm{kHz}$. Analogous to the assignment of both sites in $\mathrm{Na}_{2} \mathrm{Ti}_{3} \mathrm{O}_{7}$ before, $C_{\mathrm{Q}, 1}$ with its large value can be assigned to the Li site within the prism and $C_{Q, 2}$ with the lower value can be related to the Li site in the octahedra. Again, VASP calculations confirmed the experimentally found quadrupolar coupling constants. $C_{\mathrm{Q}, 1}$ and $C_{\mathrm{Q}, 2}$ were calculated to be $155 \mathrm{kHz}$ and $42 \mathrm{kHz}$, respectively. The deviation from the experimental values was similar to the calculations for $\mathrm{Na}_{2} \mathrm{Ti}_{3} \mathrm{O}_{\overrightarrow{ }}$ The asymmetry parameters for the Li sites amounted to $\eta_{\mathrm{Q}, 1}=0.23$ for the $\mathrm{Li}(1)$ and $\eta_{\mathrm{Q}, 2}=0.54$ for the $\mathrm{Li}(2)$ site. Therefore, the assumption of axial symmetry for the extraction of $C_{Q}$ from the experimental spectra was an approximation which was still in good accordance with theory. EFG parameters for both $\mathrm{Na}_{2} \mathrm{Ti}_{3} \mathrm{O}_{7}$ and $\mathrm{Li}_{2} \mathrm{Ti}_{3} \mathrm{O}_{7}$ are summarized in Table 1 .

Figure $4 \mathrm{~b}$ shows a ${ }^{6} \mathrm{Li}$ MAS NMR spectrum at a spinning rate of $v=15 \mathrm{kHz}$ and at $T=299 \mathrm{~K}$. The spectrum exhibits two contributions with chemical shifts of $1.37 \mathrm{ppm}(\operatorname{Li}(1))$ and $0.17 \mathrm{ppm}(\operatorname{Li}(2))$. We used dmfit for fitting the two signals 
Table 1: Quadrupolar coupling constants and asymmetry parameters derived from ${ }^{23} \mathrm{Na}$ and ${ }^{7} \mathrm{Li}$ NMR spectra and theoretical calculations using VASP. See text.

\begin{tabular}{llrlr}
\hline & $C_{\mathrm{Q}, 1}$ & $\boldsymbol{\eta}_{\mathrm{Q}, 1}$ & \multicolumn{1}{c}{$\boldsymbol{C}_{\mathrm{Q}, 2}$} & $\boldsymbol{\eta}_{\mathrm{Q}, 2}$ \\
\hline $\mathrm{Na}_{2} \mathrm{Ti}_{3} \mathrm{O}_{7}$ (exp) & $3.33 \mathrm{MHz}$ & 0.56 & $0.86 \mathrm{MHz}$ & 0.70 \\
$\mathrm{Na}_{2} \mathrm{Ti}_{3} \mathrm{O}_{7}$ (theo) & $4.03 \mathrm{MHz}$ & 0.22 & $1.25 \mathrm{MHz}$ & 0.60 \\
$\mathrm{Li}_{2} \mathrm{Ti}_{3} \mathrm{O}_{7}$ (exp) & $112 \mathrm{kHz}$ & - & $56 \mathrm{kHz}$ & - \\
$\mathrm{Li}_{2} \mathrm{Ti}_{3} \mathrm{O}_{7}$ (theo) & $155 \mathrm{kHz}$ & 0.23 & $42 \mathrm{kHz}$ & 0.54 \\
\hline
\end{tabular}

each with a Lorentzian. Using the different integrals, we compared the occupancies of both Li sites. At $299 \mathrm{~K}$, both Li sites are equally occupied. A coalescence was observed at higher spinning rates. The beginning of the coalescence is visible at $v=20 \mathrm{kHz}$ corresponding to a temperature $T=307 \mathrm{~K}$. Full coalescence of the ${ }^{6} \mathrm{Li}$ NMR line is observed at $v=30 \mathrm{kHz}$ or $T=327 \mathrm{~K}$. At this temperature, the population of the $\operatorname{Li}$ sites $\operatorname{Li}(1): \operatorname{Li}(2)$ changes from $1: 1$ to $1: 2$. Due to the coalescence of the NMR line we assumed that the Li jump rate between the two sites is about $10^{5}$ $\mathrm{s}^{-1}$ at $327 \mathrm{~K}$.

Thus, it is possible to obtain not only structural information from solid-state NMR spectra, but also information on cation dynamics which is dealt with in more detail in the following section.

\subsection{Solid-state NMR: dynamics}

Information on $\mathrm{Na}$ dynamics in $\mathrm{Na}_{2} \mathrm{Ti}_{3} \mathrm{O}_{7}$ was obtained only by the observation of the coalescence of the quadrupolar contribution to the ${ }^{23} \mathrm{Na}$ NMR line and via the low-temperature flank of the diffusion-induced peak of the ${ }^{23} \mathrm{Na}$ NMR SLR rate. Similar to the ${ }^{6} \mathrm{Li}$ MAS NMR spectra, the temperature-dependent static ${ }^{23} \mathrm{Na}$ NMR spectra show a coalescence of the quadrupolar contribution at $433 \mathrm{~K}$. Again, the Na jump rate can be estimated to be approx. $10^{5} \mathrm{~s}^{-1}$. In Figure 5, the ${ }^{23} \mathrm{Na}$ NMR SLR rates in the laboratory $\left(T_{1}^{-1}\right)$ and in the rotating $\left(T_{1 \rho}^{-1}\right)$ frame of reference are displayed. SLR rates in the laboratory frame of reference were measured at a ${ }^{23} \mathrm{Na}$ Larmor frequency of $158 \mathrm{MHz}$. The ${ }^{23} \mathrm{Na}$ NMR SLR $\rho$ rates were recorded using a spin-lock pulse corresponding to an effective Larmor frequency of 15 kHz. Both SLR rates exhibit the diffusion-induced contribution only after appropriate background correction using a temperature-dependent power law $T^{-\alpha}$. In both cases, the power law exponent $\alpha$ is found to be $\alpha \approx 5$. According to [7], the power law can be attributed to different non-diffusive contributions, and a large value of the exponent may point to more than one non-diffusive contribution to the background. Here, we suppose that the large value of the exponent $\alpha$ is 


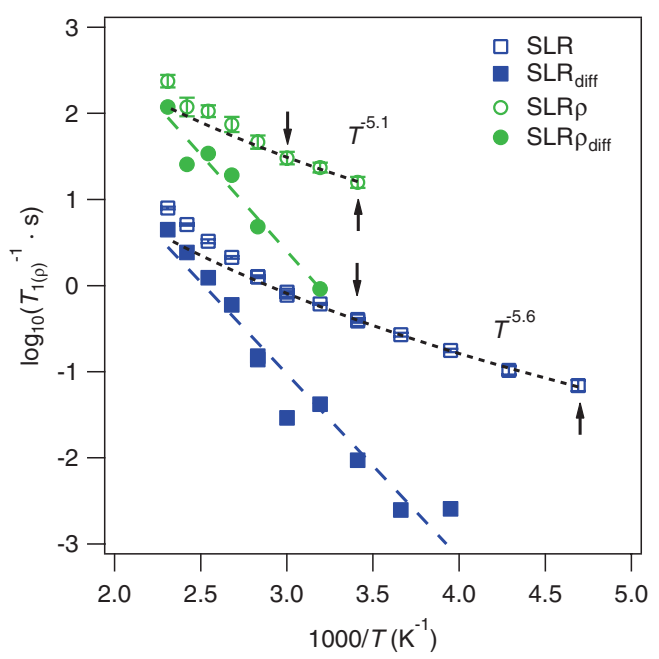

Fig. 5: ${ }^{23} \mathrm{Na} \operatorname{NMR} \operatorname{SLR}\left(\omega_{0} / 2 \pi=158.8 \mathrm{MHz}\right)$ and $\operatorname{SLR} \rho\left(\omega_{1} / 2 \pi=15 \mathrm{kHz}\right)$ rates plotted versus inverse temperature. Open symbols denote the measured relaxation rates. For a background correction, a fit of the low-temperature data with a power law was used (short-dashed lines). The exponent is also shown. After background correction, the relaxation rates due to ionic motion only are depicted by closed symbols. These corrected relaxation rates showing the low-temperature flank only were fitted (long-dashed lines) to yield the activation energies of the local Na motion.

due to spin-phonon coupling. As shown by van Kranendonk [58], the exponent can take values between 2 and 7, depending on the temperature. A power law of $T^{7}$ is valid for temperatures up to $0.02 \Theta$ where $\Theta$ is the Debye temperature. The exponent of two holds for temperatures higher than $0.5 \Theta$. With thermodynamic data published on $\mathrm{Na}_{2} \mathrm{Ti}_{3} \mathrm{O}_{7}[20,59]$, we estimated a Debye temperature $\Theta \approx 600 \mathrm{~K}$. Thus, at temperatures below $300 \mathrm{~K}, \alpha>2$ due to spin-phonon coupling seems to be possible.

The diffusive contribution of the ${ }^{23} \mathrm{Na}$ NMR SLR rates is mainly of quadrupolar nature due to the large quadrupolar moment of ${ }^{23} \mathrm{Na}$ [60]. Non-selective pulses were used to avoid the measurement of a distribution of $T_{1}$ relaxation times [61]. Due to the fact that the quadrupolar interaction is normally weaker than dipolar interaction, non-diffusive contributions could have a larger influence in the overall SLR rate of ${ }^{23} \mathrm{Na}$ than of ${ }^{7} \mathrm{Li}$.

With the SLR rates showing the diffusive contribution only, we could access the activation energy from the low-temperature flanks. Within the investigated temperature range, no rate maxima and high-temperature flanks were observed. The activation energies of 0.41 (3) $\mathrm{eV}$ from $T_{1}^{-1}$ and 0.43 (5) $\mathrm{eV}$ from $T_{1 \rho}^{-1}$ are identical and refer to short-range Na motion on the atomic scale. 
For the description of the $\mathrm{Li}$ motion in $\mathrm{Li}_{2} \mathrm{Ti}_{3} \mathrm{O}_{\rightarrow}$, static, temperature-dependent ${ }^{7} \mathrm{Li}$ NMR spectra gave a first insight. In Figure 6a, static ${ }^{7} \mathrm{Li}$ NMR spectra are displayed for a temperature range from 213 to $473 \mathrm{~K}$. With increasing temperature, narrowing of the central line was observed. This is due to the increasing averaging of the ${ }^{7} \mathrm{Li}$ dipolar interaction as the Li ions move faster. The motional narrowing $(\mathrm{MN})$ of the central line is explicitly shown in Figure $6 \mathrm{~b}$ where its full width at half maximum (FWHM) is plotted versus temperature. In the rigid lattice regime at low temperatures, the FWHM is constant. At a temperature of about $320 \mathrm{~K}, \mathrm{MN}$ sets in. The remaining minimum line width in the region of extreme narrowing is determined by the inhomogeneity of the external magnetic field. From the MN data, a Li jump rate and an activation energy can roughly be estimated. Using the expression $\tau_{\mathrm{MN}}^{-1}=2 \pi v_{\mathrm{rl}}$ (with $v_{\mathrm{rl}}$ being the rigid lattice FWHM), the jump rate $\tau_{\mathrm{MN}}^{-1}$ was calculated to be about $3.8 \times 10^{4} \mathrm{~s}^{-1}$ at $365 \mathrm{~K}$ (inflection point). The activation energy $E_{\mathrm{A}}$ was determined by the empirical expression of Hendrickson and Bray [62] yielding $0.58(5) \mathrm{eV}$.

With the help of ${ }^{6} \mathrm{Li} 2 \mathrm{D}$ NMR EXSY, the exchange between the two Li sites was investigated. In Figure 7a and $\mathrm{b}$ the 2D NMR spectra are shown for two mixing times $t_{\mathrm{m}}, 1 \mathrm{~ms}$ and $10 \mathrm{~s}$. For the mixing time of $1 \mathrm{~ms}$, no cross peaks were observed. With increasing mixing time, an increase of the cross-peak intensity became
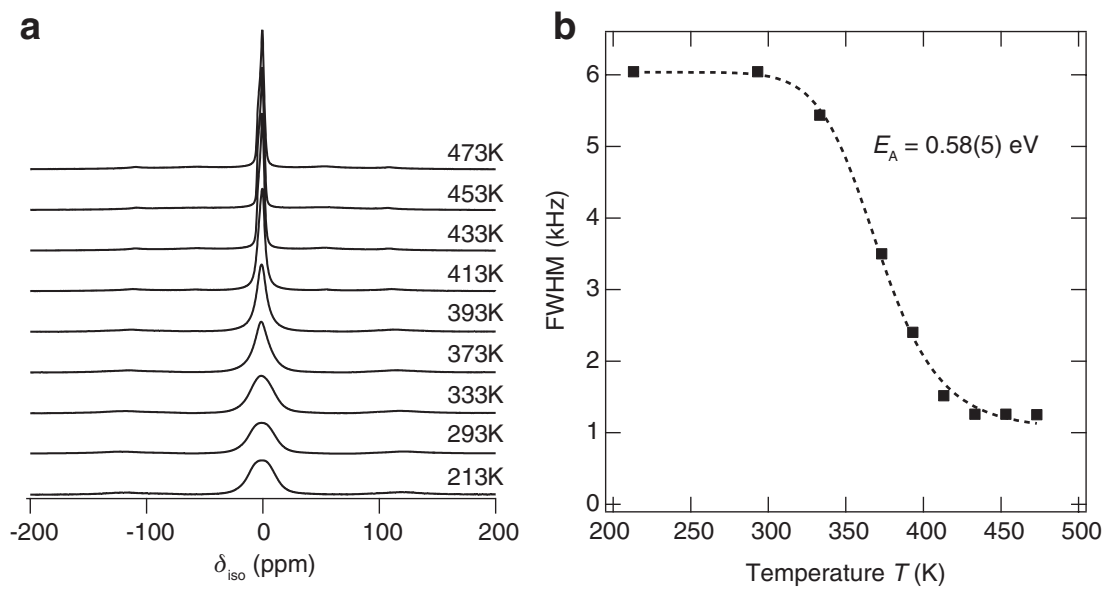

Fig. 6: (a) ${ }^{7}$ Li static NMR spectra recorded at the Larmor frequency of $\omega_{0} / 2 \pi=233.3 \mathrm{MHz}$. The spectra correspond to those shown in Figure 4a. The scaling was changed to show the full central line for each temperature. This emphasizes the effect of motional narrowing of the central line with increasing temperature. (b) Full width at half maximum (FWHM) plotted versus temperature (closed symbols). The dashed line depicts the fit using the model by Hendrickson and Bray [62] giving the activation energy of 0.58 (5) eV. 

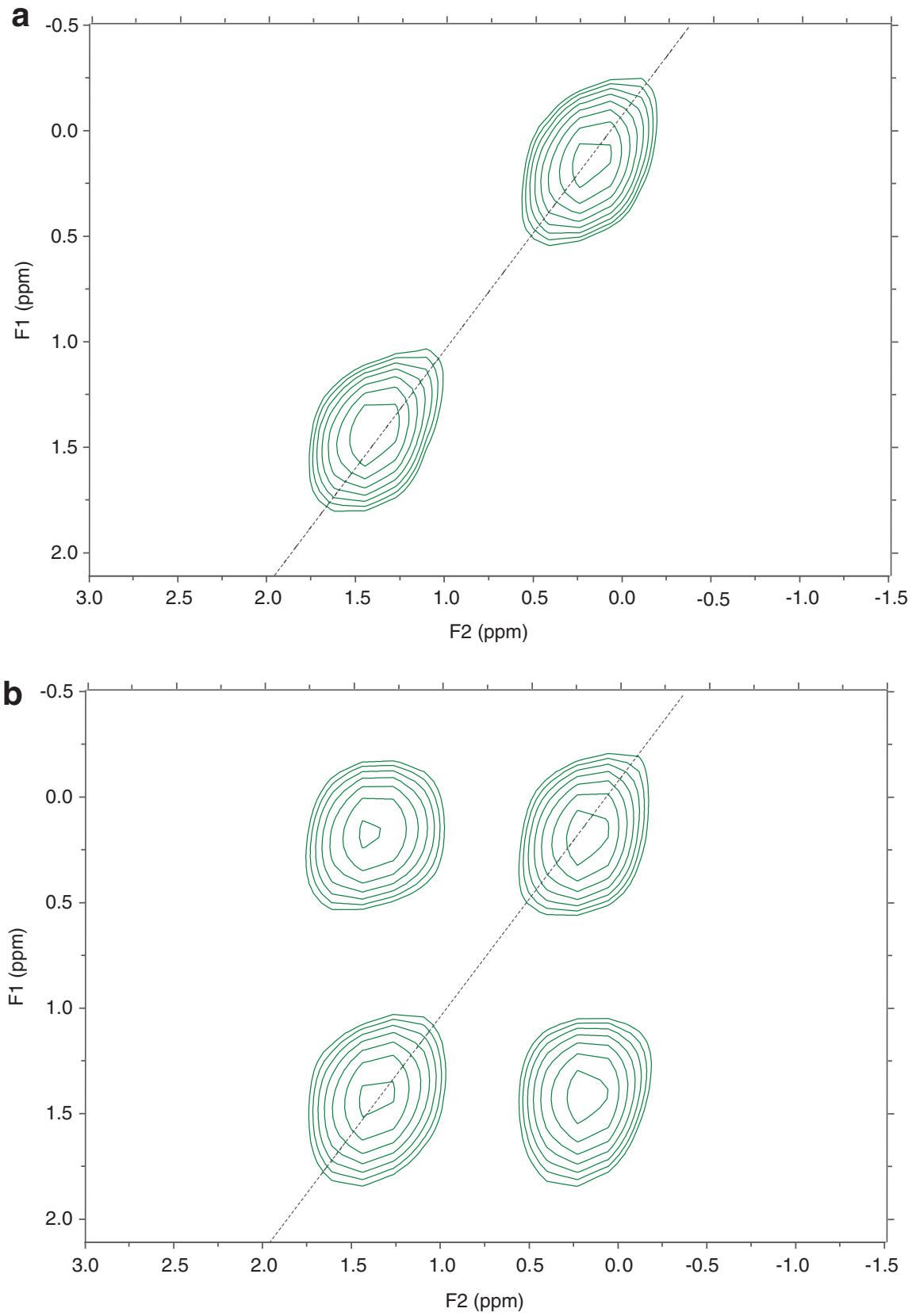

Fig. 7: ${ }^{6}$ Li 2D NMR EXSY at mixing times of (a) $1 \mathrm{~ms}$ and (b) $10 \mathrm{~s}$. Experimental parameters correspond to those noted in the caption of Figure $4 \mathrm{~b}$. At $1 \mathrm{~ms}$ mixing time, no cross-peak intensities could be observed. The cross peaks evolved with increasing mixing time until saturation in intensity at $10 \mathrm{~s}$. 


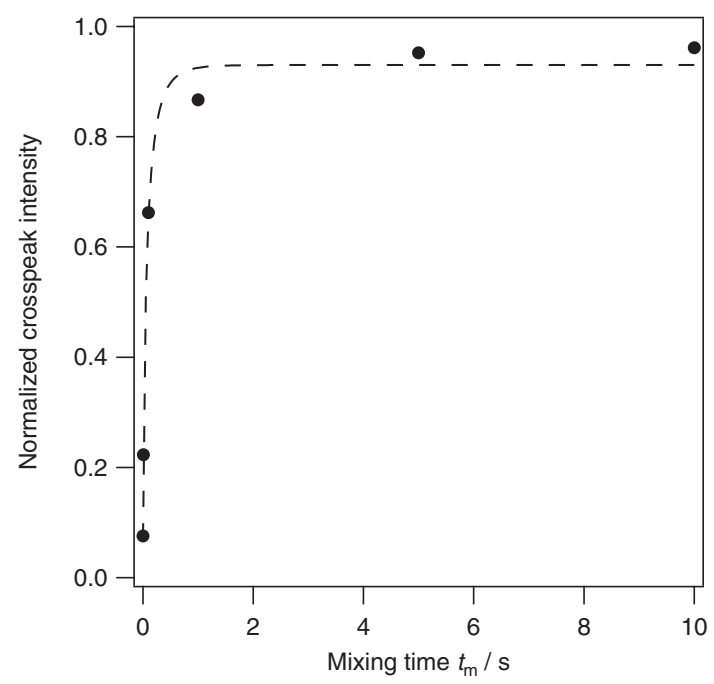

Fig. 8: Normalized cross-peak intensities plotted versus mixing time. The data was fitted using a stretched exponential function. A correlation time $\tau$ of 0.08 (2) $\mathrm{s}$ and a stretching factor $\gamma$ of 0.64 (23) were calculated.

visible. At $10 \mathrm{~s}$ mixing time, the intensity of the cross peaks was already constant. The cross peaks showed that a direct exchange between the Li sites takes place. The intensities of the cross peaks were obtained by integration. Plotting the normalized intensities vs. mixing time gave access to the Li correlation time (Figure 8). The data was fitted using a stretched exponential. The correlation time $\tau$ amounted to 0.08 (2) s at a temperature $T=300 \mathrm{~K}$ and the stretching exponent $\gamma$ to 0.6 (2). At this temperature, we observed a slow Li diffusivity which is related to the equally occupied $\mathrm{Li}$ sites $\operatorname{Li}(1)$ and $\operatorname{Li}(2)$.

Figrue 9a presents ${ }^{7} \mathrm{Li}$ NMR SLR rates for both the laboratory and rotating frame of reference. In the laboratory frame of reference $\left(\omega_{0} / 2 \pi=233.3 \mathrm{MHz}\right)$, the ${ }^{7} \mathrm{Li}$ NMR SLR rate exhibits no maximum. Only the activation energy of 0.35 (2) eV was estimated from the slope of the low-temperature flank. Using the spin-lock technique enabled us to record ${ }^{7} \mathrm{Li}$ NMR SLR $\rho$ rates in lower effective magnetic fields. A maximum in relaxation rates was observed for each field and additionally SLR $\rho$ rates on the high-temperature flank could be measured. As a first approach, activation energies from SLR and SLR $\rho$ rates may be deduced from fitting the data for each field with a Lorentzian function based on the model by Bloembergen, Purcell and Pound (BPP) [63]. The results are summarized in Table 2. The fits by Lorentzians were applied for calculating the positions of the maxima. They were not employed for the description of the data under the view of dimensionality. 
Table 2: Results of ${ }^{7} \mathrm{Li}$ NMR spin-lattice relaxation measurements carried out for various frequencies $\omega_{1} / 2 \pi$ and $\omega_{0} / 2 \pi=233.3 \mathrm{MHz}$ (cf. Figure 9a, see text).

\begin{tabular}{|c|c|c|c|c|c|}
\hline & \multirow{2}{*}{$\frac{\text { SLR }}{233 \mathrm{MHz}}$} & \multicolumn{4}{|l|}{ SLRp } \\
\hline & & $10 \mathrm{kHz}$ & $15 \mathrm{kHz}$ & $20 \mathrm{kHz}$ & $30 \mathrm{kHz}$ \\
\hline \multirow{3}{*}{$\begin{array}{l}E_{\mathrm{A}} / \mathrm{eV} \\
\tau^{-1} / \mathrm{s}^{-1}\end{array}$} & $0.35(2)$ & 0.49 (3) & 0.47 (1) & $0.42(1)$ & $0.41(2)$ \\
\hline & - & $1.26 \times 10^{5}$ & $1.89 \times 10^{5}$ & $2.51 \times 10^{5}$ & $3.77 \times 10^{5}$ \\
\hline & - & $402 \mathrm{~K}$ & $409 \mathrm{~K}$ & $415 \mathrm{~K}$ & $426 \mathrm{~K}$ \\
\hline
\end{tabular}
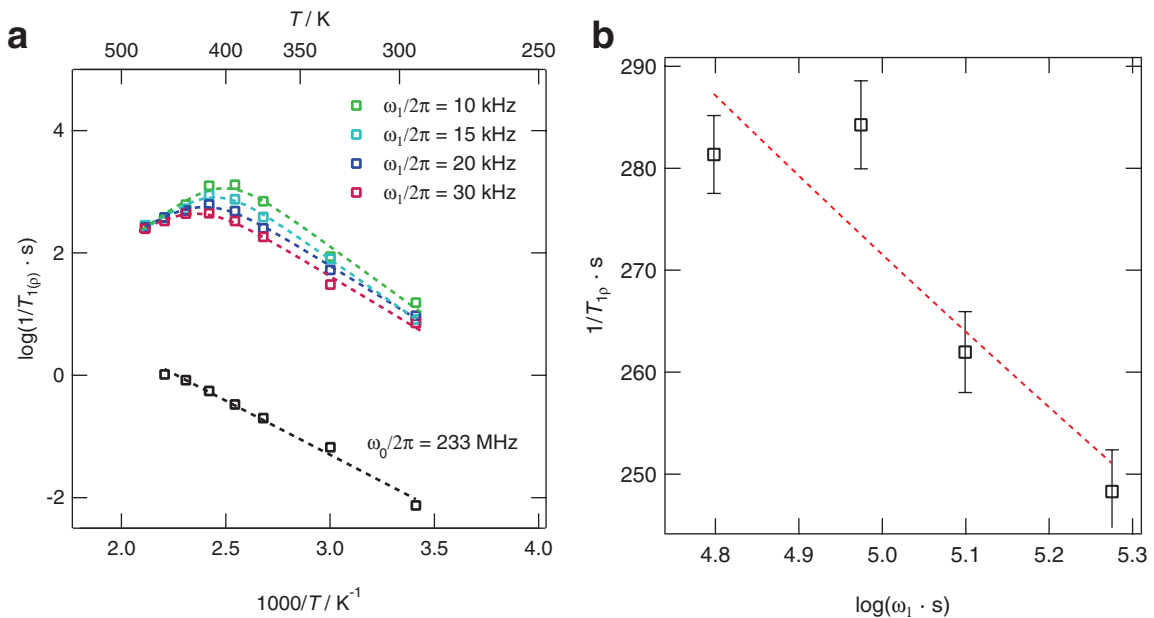

Fig. 9: (a) ${ }^{7} \operatorname{Li} \operatorname{NMR} \operatorname{SLR}\left(\omega_{0} / 2 \pi=233.3 \mathrm{MHz}\right)$ and $\operatorname{SLR} \rho\left(\omega_{1} / 2 \pi\right)$ rates plotted versus inverse temperature. The relaxation rates did not show any non-diffusive background. See text for details. (b) Frequency dependence of the SLR $\rho$ rates at $T=473 \mathrm{~K}$. The SLR $\rho$ rate is plotted versus $\log \left(\omega_{1}\right)$. The observed linear dependence of the data corresponds to the behavior of a 2D ion conductor [64].

The empirical expression by Richards [64] for SLRp rates induced by 2D diffusion led to the same fit results as BPP as far as the activation energy and the jump rate are concerned. However, the frequency dependence of the high-temperature flank is used for the investigation of the dimensionality of the Li motion [64]. The SLR $\rho$ rates for $T=470 \mathrm{~K}$ are plotted versus $\log \left(\omega_{1}\right)$ in Figure $9 \mathrm{~b}$. According to the expected logarithmic frequency dependence of the SLR rate in the case of twodimensional diffusion, a straight line should be observed, which is the case for $\mathrm{Li}_{2} \mathrm{Ti}_{3} \mathrm{O}_{7}$ (Figure 9b). Thus, we could reveal that the Li motion occurs mainly within the Ti-O layers with an average activation energy of $0.43 \mathrm{eV}$. This is similar to the 


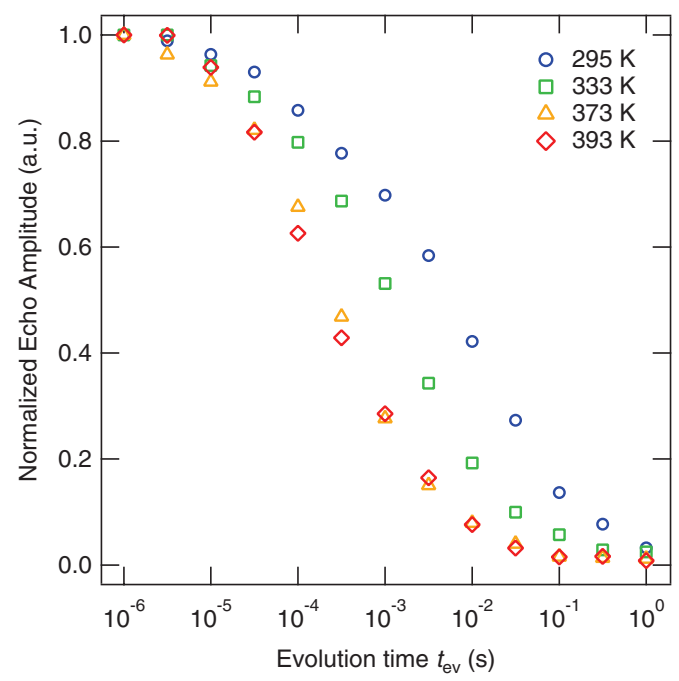

Fig. 10: ${ }^{7} \mathrm{Li} \mathrm{NMR}\left(\omega_{0} / 2 \pi=233.3 \mathrm{MHz}\right) \mathrm{SAE}$ transients for a temperature range from $295 \mathrm{~K}$ to $393 \mathrm{~K}$. Spin-alignment echoes were recorded using the Jeener-Broekaert pulse sequence with a preparation time $t_{\mathrm{p}}=50 \mu \mathrm{s}$. The SAE transients were normalized and fitted with a stretched exponential. The stretching exponent $\gamma$ varied around 0.35 (6) in the shown temperature range. $\mathrm{Li}$ jump rates were obtained by this fit for the given temperature range. If plotted in a separate Arrhenius graph, the activation energy of 0.48 (2) eV was calculated from the Li jump rates measured by SAE. This is comparable to the activation energies found by the other NMR methods.

results for ${ }^{23} \mathrm{Na}$ NMR SLR for $\mathrm{Na}_{2} \mathrm{Ti}_{3} \mathrm{O}_{7}$, There seems to be no change in the basic ionic motion if the cation is exchanged.

${ }^{7} \mathrm{Li}$ NMR SAE transients for different temperatures are displayed in Figure 10. The echoes were recorded using a preparation time of $t_{\mathrm{p}}=50 \mu \mathrm{s}$. Echo amplitudes were normalized and plotted vs. the logarithm of the mixing time $t_{\mathrm{m}}$. The decay of the echo amplitude was fitted using a stretched exponential function. The fit gives the correlation time $\tau_{\mathrm{SAE}}$ between two jumps as SAE depends on the local change of the electric field gradient at the site of the nuclear spin. The fit of these jump rates $\tau_{\mathrm{SAE}}^{-1}$ alone, plotted as Arrhenius graph, resulted in the activation energy $E_{\mathrm{A}}=0.48(2) \mathrm{eV}$. This is similar to the activation energies obtained by ${ }^{7} \mathrm{Li}$ NMR SLR.

The collected $\mathrm{Li}$ jump rates for $\mathrm{Li}_{2} \mathrm{Ti}_{3} \mathrm{O}_{7}$ are shown in an Arrhenius plot in Figure 11. The jump rates recorded by ${ }^{7} \mathrm{Li}$ NMR SAE, ${ }^{7} \mathrm{Li}$ NMR SLR $\rho$ and ${ }^{6} \mathrm{Li} 2 \mathrm{D}$ NMR EXSY show Arrhenius behavior over five orders of magnitude. Thus, the lithium motion faces the same potential landscape within the layers observed 


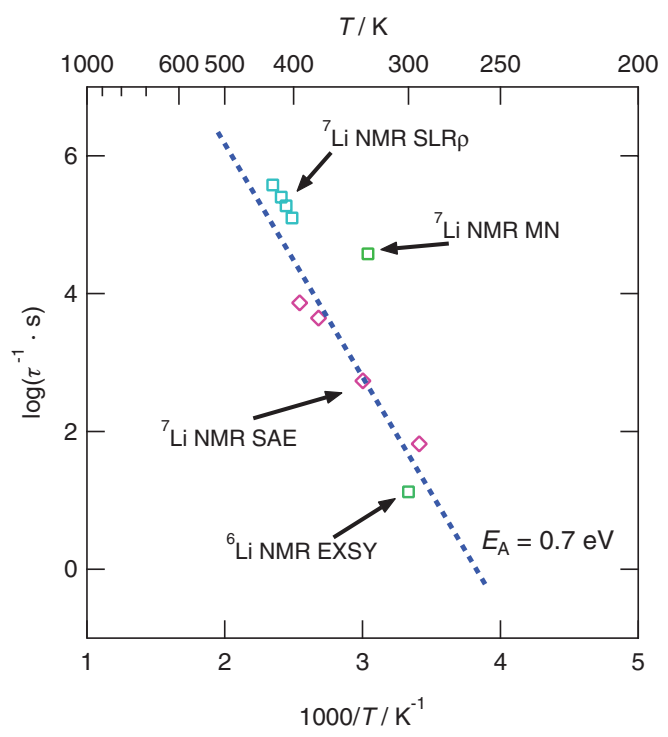

Fig. 11: $\mathrm{Li}$ jump rates for $\mathrm{Li}_{2} \mathrm{Ti}_{3} \mathrm{O}_{7}$ yielded by the different NMR methods are plotted on logarithmic scale against the inverse temperature. The dashed line is a guide to the eye. Its slope corresponds to an activation energy of $E_{\mathrm{A}}=0.7 \mathrm{eV}$.

with different NMR techniques and on different time scales. The slope of the drawn line corresponds to an activation energy of $E_{\mathrm{A}}=0.7 \mathrm{eV}$. Some deviation was observed for the Li jump rate estimated by ${ }^{7} \mathrm{Li}$ NMR MN. Altogether, the results indicate a single Li jump mechanism over five decades investigated with several complementary solid-state NMR methods.

\section{Conclusion}

Both layered $\mathrm{Na}_{2} \mathrm{Ti}_{3} \mathrm{O}_{7}$ and $\mathrm{Li}_{2} \mathrm{Ti}_{3} \mathrm{O}_{7}$ were synthesized and characterized. Structure and cation dynamics were studied in detail by solid-state NMR. ${ }^{23} \mathrm{Na}$ NMR showed structural details for the two Na sites within the unit cell. The two sites exhibited different electric field gradients whose tensor components were obtained by a fit of the ${ }^{23} \mathrm{Na}$ NMR MAS spectrum. These results were found to be in accordance with those of the theoretical calculations performed. ${ }^{6} \mathrm{Li}$ and ${ }^{7} \mathrm{Li}$ NMR spectra presented analog structure properties for $\mathrm{Li}_{2} \mathrm{Ti}_{3} \mathrm{O}_{7}$ which was prepared via ion-exchange. Cation dynamics were investigated for both materials. As a first insight, ${ }^{23} \mathrm{Na}$ NMR SLR and SLR $\rho$ yielded the activation energies for local Na motion. Further detailed 
studies with an extension of the temperature range might identify the supposed low-dimensional Na motion. ${ }^{6} \mathrm{Li}$ and ${ }^{7} \mathrm{Li} \mathrm{NMR}$ methods were used to elucidate the Li motion in layered $\mathrm{Li}_{2} \mathrm{Ti}_{3} \mathrm{O}_{\overrightarrow{ }}{ }^{6} \mathrm{Li}$ 2D NMR EXSY showed a direct correlation of both Li sites and gave a value for the Li jump rate. ${ }^{7} \mathrm{Li}$ NMR SLR $\rho$ and SAE resulted in similar activation energies. ${ }^{7} \mathrm{Li}$ NMR SLR $\rho$ also confirmed the low-dimensional Li motion within the layers. ${ }^{7} \mathrm{Li}$ NMR motional narrowing tended to overestimate the jump rate obtained by the other methods. Altogether, the Arrhenius plot of the Li jump rates indicated one jump mechanism in the investigated temperature range. The Li jump rates could be detected over five orders of magnitude and the activation energy turned out to be about $0.7 \mathrm{eV}$. These results have recently been confirmed by impedance spectroscopy to be published separately.

Acknowledgement: We thank Prof. Feldhoff for access to the scanning electron microscope and Dr. Licht for carrying out the measurements at the SEM. Financial support by the DFG in the frame of the Research Unit FOR 1277 (molife) is gratefully acknowledged.

\section{References}

1. Z. Yang, D. Choi, S. Kerisit, K. M. Rosso, D. Wang, J. Zhang, G. Graff, J. Liu, J. Power Sources 192 (2009) 588.

2. G.-N. Zhu, Y.-G. Wang, Y.-Y. Xia, Energy Environ. Sci. 5 (2012) 6652.

3. W. Küchler, P. Heitjans, A. Payer, R. Schöllhorn, Solid State Ionics 70-71 (1994) 434.

4. R. Winter, P. Heitjans, J. Non-Cryst. Solids 293-295 (2001) 19.

5. R. Winter, P. Heitjans, J. Phys. Chem. B 105 (2001) 6108.

6. T. Bredow, P. Heitjans, M. Wilkening, Phys. Rev. B 70 (2004) 115111.

7. M. Wilkening, P. Heitjans, Phys. Rev. B 77 (2008) 24311.

8. M. M. Islam, T. Bredow, Z. Phys. Chem. 229 (2015) 1265.

9. R. Knobel, H. Behrens, N. I. Schwarzburger, M. Binnewies, I. Horn, Z. Phys. Chem. 229 (2015) 1289.

10. D. Wiedemann, M. M. Islam, S. Nakhal, A. Senyshyn, T. Bredow, M. Lerch, J. Phys. Chem. C 119 (2015) 11370.

11. C. V. Chandran, P. Heitjans, in: G. A. Webb (Ed.): Annual reports on NMR spectroscopy, Academic Press, Amsterdam (2016), P. 1.

12. M. Wilkening, W. Iwaniak, J. Heine, V. Epp, A. Kleinert, M. Behrens, G. Nuspl, W. Bensch, P. Heitjans, Phys. Chem. Chem. Phys. 9 (2007) 6199.

13. M. Wilkening, R. Amade, W. Iwaniak, P. Heitjans, Phys. Chem. Chem. Phys. 9 (2007) 1239.

14. M. Wilkening, J. Heine, C. Lyness, A. Armstrong, P. Bruce, Phys. Rev. B 80 (2009).

15. W. Iwaniak, J. Fritzsche, M. Zukalová, R. Winter, M. Wilkening, P. Heitjans, Def. Diff. Forum 289-292 (2009) 595.

16. L. Wu, D. Buchholz, D. Bresser, L. Gomes Chagas, S. Passerini, J Power Sources 251 (2014) 379. 
17. W. Schmidt, P. Bottke, M. Sternad, P. Gollob, V. Hennige, M. Wilkening, Chem. Mater. 27 (2015) 1740.

18. S. Kikkawa, F. Yasuda, M. Koizumi, Mater. Res. Bull. 20 (1985) 1221.

19. A.-L. Sauvet, S. Baliteau, C. Lopez, P. Fabry, J. Solid State Chem. 177 (2004) 4508.

20. M. Holzinger, A. Benisek, W. Schnelle, E. Gmelin, J. Maier, W. Sitte, J. Chem. Thermodyn. 35 (2003) 1469.

21. Y. An, Z. Li, H. Xiang, Y. Huang, J. Shen, Centr. Eur. J. Phys. 9 (2011) 1488.

22. K. Chiba, N. Kijima, Y. Takahashi, Y. Idemoto, J. Akimoto, Solid State Ionics 178 (2008) 1725.

23. A. Kuhn, M. Kunze, P. Sreeraj, H. D. Wiemhöfer, V. Thangadurai, M. Wilkening, P. Heitjans, Solid State Nucl. Magn. Reson. 42 (2012) 2.

24. M. Wilkening, P. Heitjans, Chem. Phys. Chem. 13 (2012) 53.

25. P. Heitjans, S. Indris, M. Wilkening, Diffus. Fundam. 2 (2005) 1.

26. P. Heitjans, J. Kärger (Eds.): Diffusion in condensed matter: methods, materials, models, Springer, Berlin and New York (2005).

27. S. Andersson, A. D. Wadsley, Acta Crystallogr. 14 (1961) 1245.

28. M. Catti, I. Pinus, A. Scherillo, J. Solid State Chem. 205 (2013) 64.

29. G. Bergerhoff, I. D. Brown, in: F. H. Allen (Ed.): Crystallographic databases: information content, software systems, scientific applications, Int. Union of Crystallography, Chester (1987), P. 77.

30. J. Rodríguez-Carvajal, Physica B Condensed Matter 192 (1993) 55.

31. K. Brandenburg, H. Putz, Diamond - crystal and molecular structure visualization, crystal impact - Dr. H. Putz and Dr. K. Brandenburg GbR, Kreuzherrenstr. 102, 53227 Bonn, Germany (2014).

32. K. R. Thruber, R. Tycko, J. Magn. Res. 196 (2009) 84.

33. E. Fukushima, Roeder, Stephen B. W, Experimental pulse NMR: a nuts and bolts approach, Addison-Wesley Pub. Co., Advanced Book Program, Reading, Mass (1981).

34. D. Ailion, C. P. Slichter, Phys. Rev. Lett. 12 (1964) 168.

35. D. Ailion, C. P. Slichter, Phys. Rev. 137 (1965) A235.

36. D. Wolf, Phys. Rev. B 10 (1974) 2710.

37. R. Böhmer, J. Magn. Res. 147 (2000) 78.

38. R. Böhmer, T. Jörg, F. Qi, A. Titze, Chem. Phys. Lett. 316 (2000) 419.

39. F. Qi, T. Jörg, R. Böhmer, Solid State Nucl. Magn. Reson. 22 (2002) 484.

40. J. Jeener, P. Broekaert, Phys. Rev. 157 (1967) 232.

41. X.-P. Tang, R. Busch, W.L. Johnson, Y. Wu, Phys. Rev. Lett. 81 (1998) 5358.

42. M. Wilkening, P. Heitjans, J. Phys. Condens. Matter 18 (2006) 9849.

43. M. H. Levitt, Spin dynamics: basics of nuclear magnetic resonance, Wiley, Chichester, UK (2008).

44. D. Marion, M. Ikura, R. Tschudin, A. Bax, J. Magn. Res. 85 (1989) 393.

45. G. Kresse, J. Hafner, Phys. Rev. B 47 (1993) 558.

46. G. Kresse, J. Hafner, Phys. Rev. B 49 (1994) 14251.

47. G. Kresse, J. Furthmüller, Comp. Mater. Sci. 6 (1996) 15.

48. G. Kresse, J. Furthmüller, Phys. Rev. B 54 (1996) 11169.

49. J. P. Perdew, K. Burke, M. Ernzerhof, Phys. Rev. Lett. 77 (1996) 3865.

50. J. P. Perdew, K. Burke, M. Ernzerhof, Phys. Rev. Lett. 78 (1997) 1396.

51. P. E. Blöchl, Phys. Rev. B 50 (1994) 17953.

52. G. Kresse, D. Joubert, Phys. Rev. B 59 (1999) 1758.

53. H. J. Monkhorst, J. D. Pack, Phys. Rev. B 13 (1976) 5188. 
54. O. V. Yakubovich, V. V. Kireev, Crystallogr. Rep. 48 (2003) 24.

55. M. C. Morris, Standard x-ray diffraction powder patterns, U.S. Dept. of the Commerce, National Bureau of Standards; G.P.O., Washington, D.C. (1979).

56. D. Massiot, F. Fayon, M. Capron, I. King, S. Le Calvé, B. Alonso, J.-O. Durand, B. Bujoli, Z. Gan, G. Hoatson, Magn. Reson. Chem. 40 (2002) 70.

57. J. Langer, V. Epp, P. Heitjans, F. A. Mautner, M. Wilkening, Phys. Rev. B 88 (2013) 94304.

58. J. van Kranendonk, Physica 20 (1954) 781.

59. G. Eriksson, A. D. Pelton, MTB 24 (1993) 795.

60. P. Pyykkö, Mol. Phys. 106 (2008) 1965.

61. J. P. Yesinowski, J. Magn. Res. 252 (2015) 135.

62. J. Hendrickson, P. Bray, J. Magn. Res. 9 (1973) 341.

63. N. Bloembergen, E. M. Purcell, R. V. Pound, Phys. Rev. 73 (1948) 679.

64. P. M. Richards, in: M. B. Salamon (Ed.): Physics of superionic conductors, Springer, Berlin Heidelberg (1979), P. 141. 